\title{
The Impact of Environmental and Regional Factors on the Vernacular Architecture: Special Reference to City of Qazvin
}

\author{
Abolfazl Saroukhani*, Majid Shahbazi \\ Department of Technical and Engineering, Zanjan Branch, \\ Islamic Azad University, Zanjan, Iran \\ Study Area: Qazvin, Iran \\ Coordinates: $36^{\circ} 16^{\prime} \mathrm{N} ; 50^{\circ} \mathrm{oo} \mathrm{E}$
}

Key words: Sustainable architecture, Environmental conditions, Climatic conditions

\section{Introduction:}

The apparent effect of industrialisation and modern communication system of society on the base of architecture is quite obvious, and every day we could see different designs and architectural forms designs. Such forms perhaps made according to a set of terms and conditions regardless of the specific conditions but mainly focused on lucrative imitation. But today, due to the shortcomings and problems in the field of conservation and eff icient use of energy and also according to optimising the architectural spaces and the changing in our requirement from performance architecture, we need to define a new approach to architecture called "sustainable architecture". For more practical, it must be recognised general principles of such type of architecture. Buildings must be spacious clean having the healthy environment based on effective utilisation of natural resources where ecological principles must be created (Hasani Shirkoohi et al., 2014). Indeed, the concept of sustainability in architecture does not mean to create buildings that can be sustained for many years because a building with several hundred years old is not coordinated with the needs of the

\section{Abstract}

Iranian architecture has an ancient history.In certain cases, universally it serves as the root principles of the architectural. In fact, the environment and the ambient circumstances, customs and culture play an important role in creating a sustainable architecture. Understanding the vernacular architecture of the city means cognition of society. Stability existed in the traditional architecture because it was created by own domestic people. Also, the sustainable architecture is eco-friendly in nature. The aim of this article is to review the effect of regional and environmental factors on vernacular architecture forms (The case of study is Qazvin). The current study is descriptive - analytical in which we analysed and discussed the various aspects of vernacular architecture impacted by environmental and regional factors. One of the effective ways to achieve climatic design principles is reviewing the vernacular architecture patterns in the compatibility with the environment and region. Studying the parameters such as orientation, form and architectural elements in the native home of Qazvin indicates the developments in environmental issues and trying to take advantage of it.

present time. Architectures can be called sustainable which is responsive to the needs of the present. We find that in many of these buildings, cultural and climatic conditions are completely considered but it's not coordinated with present architecture needs, urban lifestyle and present limitations. Conditions and indicators which define a typical architecture as "sustainability" would not be practical for coming future. In the new issue of sustainable architecture, we are going to reduce the destructive effects of new architecture on the environment and by using homogeneous materials and special design of climate we can also save energy consumption (Jafari \& Esmaeelpour, 2015).

Coordination and Compatibility with nature and the environment for minimum damage to nature: sustainable design begins with an understanding of the environment. If we are will aware about our environment, we can avoid damaging it. In this regard, great efforts were made in Organic architecture and Ecotech architectural. As per organic architecture building should be designed and implemented in such a way so that it have the least damage and manipulation on nature, in other words, it should be a

*Corresponding Author: abolfazlsarokhani1395@gmail.com 
part of the natural surroundings, and construction materials and colours are in harmony with nature in a sustainable manner. The sustainable designer must analyse the natural surroundings to provide the right and suitable solution to integrate artefacts in nature. In Ecotech architecture, the environment with using biodegradable or recyclable fuel and energy play an important role (Soleymanpour et al., 2015).

Cultural and regional identity: designers should always consider the culture and regional identity which has three following elements:

A. Using regional materials as much as they can

B. Using regional labour

C. Using regional signs and elements (Fig. 1)

In Iranian traditional architecture buildings according to culture and ethnic identity has been given priority and in which composition and architecture were never against religious beliefs and culture. Even decorative elements which are considered as architecture subsidiary organs have not been exempt from this rule. Five principles are always considered; being popular, avoiding futility, introspection, worship and the use of local materials (general principles mentioned in the Pirnia's book) is considered. In the old traditional architecture (in previous centuries), the environment condition has always been concerned which confirmed the correct impact of culture, religion and traditions of the people of Iran on the construction and architecture. These are the principles which have been overlooked in the present days and the rehabilitation of such principle in accordance with contemporary architecture would create a new approach to the contemporary architecture of Iran (Manzano-Agugliaro, 2015). The weather and climatic conditions in this type of architecture have always been an issue that people over thousands of years of experienced. There are a lot of problems in the warm and dry area or hot and humid climates that should be considered by architects. Hard summers and cold winters of the desert and in some cases, dust storms and dry and hot winds have led people to think (Tavassoli, 2016).

Ahadi \& Haeri, (2013) shed some light on Qazvin's vernacular structure in which the form of direction and the sample of building establishment; the approach to work on the land; the characteristics of outdoor, indoor, and semioutdoor spaces; and the features of the used material in different samples were reported. The typology of Qazvin's vernacular buildings shows that under all architectural aspects, the adaptability with the environmental conditions and the climate characteristics of the region have been considered. For instance, the direction of building settlement is matched with the direction of the sun and the direction of wind blowing and the communication sample of outdoor and indoor spaces, Its pattern in indoors and outdoors spaces around the yard and underground usage that is matched with the thermal need at the different seasons of the year. Yaghoubzadeh \& ZendeDel (2013) explained the indices of comfort and presented procedures of climate designing in Qazvin's architecture and urbanisation. Based on their findings,

Qazvin's climate should be considered having a relatively warm and dry climate with cold winters in which the avoidance of cold in winter has been given more priority than the heat in summer.

Dogan et. al., (2014) tested the relationship between organisation strategies, the policies of human integrated resources and the operation of work. It was observed that the high rate of changing environment led installations towards a more participative management understanding, empowerment, active choice, and employment policies.

Dili et. al., (2010) have investigated a comparative research during different times of the rainy season and analysed the inactive control methods of Kerala's traditional architecture for a convenient indoor. The traditional architecture of Kerala, a state that is located along the west south coast of India is recognised for its approaches of using of its natural and inactive methods for the convenient indoor. Although some efforts have tried for analysing the traditional architecture of Kerala where they have been only concentrated on quality method. The gist of the research has shown that when the temperature of the outdoor is below normal, the building system tries to retain the inside air temperature at a higher degree but comfort and if the temperature of outdoor is above normal, the inside maintains at the lower degree but comfort. This is clear that a continuous flow of breeze is retained inside the building regardless of the wind outside.

\section{General Survey and Obsevations:}

The city of Qazvin, the central and the largest city of the Qazvin province is located between the geographical length of 50-oo degree and the width of 36-15 degree at the height of 1277 meters from above the sea level. This city is limited to Roodbar and Koohin from north, Alvand and Abyek from east, Takestan from the west, and Buin Zahra from the south. Our survey was a descriptive-analytic type in which we have also analysed the forming aspects of the vernacular architecture taking into the consideration the 
environmental and regional factors (Heath, 2009).

The impact of climate changes on vernacular architecture in Qazvin: in various old houses, the level of the yard is about half to one meter lower than the level of the alley. The low level of the building causes the soil mass to decrease the heat exchange of inside and outside like the thermal insulator. Most of the buildings are constructed with two or three floors. In such case, the lower floor is sometimes completely at the same level of the yard and sometimes 1 or 1.5 meters below the earth level.

Choosing the orientation/direction of building formation is dependent on two factors; wind and sunlight. According to the required thermal, healthy, and mental conditions, the building should be established so that it uses the best of the sun (Kasmaei, 2003). The best building orientation is related to 20 -degree limitation of the west south to 45 -degree east south so that to receive radiant heat on winter while it receives the least heat on summer. On the other hand, the prevalent wind direction in Qazvin is 135 degrees and on two last months of the spring, it is 270 degrees. In the analysis of vernacular house samples the same orientation can be observed (Ghobadian \& Chaisaz, 2015).

In these regions, the buildings side wall must have a suitable thermal resistance to prevent the waste of inside heat of the building. In these houses, the walls are mostly thick. The outside walls high thickness cause the decrease of heat transfer and the mass of the material of the inside walls performs as heat storage.

\section{Conclusion:}

One of the effective methods to achieve the principles of climate designing is the analysis of vernacular architecture samples in adaptability with environmental and regional conditions. The study of cases such as orientation, form, and the analysis of architecture elements in vernacular houses of Qazvin indicate the builders' attention to environmental matters and effort for its utilization. The consideration of the direction of sun and wind flow in the establishment of living space on different seasons of the year are the examples of this case. In other words, the vernacular buildings in terms of possessing the climate structure have the ability to adapt the environmental conditions, the ability to face climate critical conditions, and using the facilities of the natural environment around them.

\section{References:}

Ahadi, P \& Haeri, N. (2013): Analyzing the Climatic Structure in Residual- Geological Architecture of Qazvin. National Conference on Sustainable Architecture and Urban Development. Bukan, Iran.

Dili, A.S., Naseer, M.A., \& Varghese, T.Z. (2010): Passive control methods of Kerala traditional architecture for a comfortable indoor environment: comparative investigation during various periods of rainy season. Build. Environ., 45(10):22182230.

Dogan, B., Özdemirci, A. \& Güngör, N. (2014): A Research on Competitive Strategies, Environmental Factors and Human Resources Architecture Relations. Int. Bus. Res., 7(3):115-128.

Ghobadian, V. \& Elham, C-S. (2015): The Effect of Culture on Ecological- Climatic Architecture. Third National Conference on Architecture, Restoration, Sustainable Urban Development and the Environment. Hamedan, Iran.

Hasani Shirkoohi, S., Omidi, R., Omidi, M. \& Masoud, E. (2014): The Effect of the Traditional Architecture and Ecological Culture on Tourism in the Order of Sustainable Development. Second National Conference of Architecture, Civil Engineering and Urban Environment. Hamedan, Iran .

Heath, K. (2009): Vernacular Architecture and Regional Design. Pub. by: Routledge (Taylor \& Francis group).

Jafari, B. \& Esmaeelpour R.A.A. (2015): A Survey of Ecological Architecture and a Glance at the Principles and Features of Ecology Oriented Architecture. International Conference on Humans, Architecture, Civil Engineering and Town. Tabriz. Institute for Strategic Studies in Architecture.

Kasmaei, M. (2003): Climate and Architecture, Isfahan. Khak Publication.

Manzano-Agugliaro, F., Montoya, F.G., Sabio-Ortega, A. \& GarcíaCruz, A. (2015): Review of bioclimatic architecture strategies for achieving thermal comfort. Renew. Sust. Energ. Rev., 49:736-755.

Soleymanpour, R., Parsaee, N., \& Banaei, M. (2015): Climate Comfort Comparison of Vernacular and Contemporary Houses of Iran. Procedia-Soc. Behav. Sci., 201:49-61.

Tavassoli, M. (2016): Urban Form and Architecture in the Hot Environment Zone of Iran. In: Urban Structure in Hot Arid Environments (pp. 101-106).Pub.: Springer International Publishing.

Yaghoubzadeh, N. \& ZendeDel, A. (2013): Analyzing Comfort indices and Presenting Climatic Design Solutions in the Architecture and Urbanism of Qazvin city. First National Conference on Geography, Urban Planning and Sustainable Development. Koomesh Environment Forum, University of the aviation industry, Tehran, Iran. 